\title{
Modified Clays as an Efficient Adsorbent for Brilliant Green, Ethyl Violet and Allura Red Dyes: Kinetic and Thermodynamic Studies
}

\author{
Rahmat Ullah $^{1}$, Faiza Jan Iftikhar ${ }^{1}$, Muhammad Ajmal ${ }^{1,2}$, Afzal Shah ${ }^{1,3}$, \\ Mohammad Salim Akhter ${ }^{3}$, Haseeb Ullah', Amir Waseem ${ }^{1 *}$ \\ ${ }^{1}$ Department of Chemistry, Quaid-i-Azam University, Is-lamabad, 45320, Pakistan \\ ${ }^{2}$ Department of Chemistry, University of Education, Attock Campus, Attock, 43600, Pakistan \\ ${ }^{3}$ Department of Chemistry, College of Science, University of Bahrain, Sakhir 32038, Bahrain
}

Received: 31 July 2019

Accepted: 15 September 2019

\begin{abstract}
Clay minerals can effectively adsorb contaminants from aqueous effluents due to their good adsorption and high cation exchange capacity. However, naturally occurring clay materials possessing hydrophilic features are not especially effective for the removal of organic pollutants. Therefore, in the present work the issue of hydrophilicity is tackled by modification of the clay (Pakistan origin) to prepare organoclays. Hexadecylpyridinium chloride, cetyltrimethylammonium bromide, and sodium dodecyl sulfate were used as clay modifiers. Changes in the basal spacing of clay layers after modification with surfactants were determined through XRD analysis. Chemical compositions of the clay and organoclays were determined by FTIR spectroscopy. Surface morphology of the as-prepared organoclays was assessed from SEM analysis. The modified clays (organoclays) were tested for their ability as potential adsorbents for three dyes from water: brilliant green, ethyl violet and allura red. All three modified clays showed high adsorption characteristics by removing ( $>90 \%)$ of all three dyes with an adsorption capacity ranging from 35 to $85 \mathrm{mg} / \mathrm{g}$. The time-dependent adsorption experiments showed that the rates of adsorption of dyes on organoclays were fast, adsorbing maximum amounts of dyes ranging from 15 to 80 mins of contact time. The adsorption kinetic study revealed that the dye removal process is mainly governed by a pseudo- $1^{\text {st }}$ order mechanism. Thus, surfactant-modified clays are an excellent choice as cost-effective and efficient adsorbents for the purification of water from dye contaminants.
\end{abstract}

Keywords: organoclay, surfactant, dyes, adsorption, environmental remediation

*e-mail: waseemq2000@hotmail.com 


\section{Introduction}

The demands of fresh water are increasing day by day due to high contamination of natural resources - especially in developing countries. Human beings are constantly jeopardizing the natural eco-system by releasing wastes into water bodies [1]. The environment is continuously degraded by anthorpogenic activities, especially indusries like textiles, pigments, and plastics using diffent chemicals/dyes and posing risks to people $[2,3]$. Thus, it has been reported that dye-producing industries release a large portion of dyes directly into freshwater bodies. Although the nature and the amount of dye constituents in the effluent discharge depend on the nature of the operation in a particular industry, the textile industry is the biggest producer of disposing untreated dyes in industrial wastewater [3]. Dyes affect the diversity of the aquatic ecosystem by absorbing the sunlight entering into water bodies and thus hindering photosynthetic processes. Due to the presence of dyes in water, the wastewater characteristics also change because of high biological oxygen demand (BOD) and chemical oxygen demand (COD), leading to a polluted ecosystem. Therefore, treatment of dyecontaminated water is mandatory before their release into the sewerage system to ensure water quality standards.

Various physical, chemical and biological processes are used for the remediation of dyes from wastewater. These processes include flocculation, coagulation, adsorption, ozonation, electrochemical destruction, irradiation and aerobic or anaerobic treatment $[4,5]$. However, the adsorption process for water purification is preferred because of its low cost and no extra sludge generation $[6,7]$. Among the adsorbents, clay has been reported to act as an especially effective adsorbent for water pollutants [8]. Recent research in this area has focused on modification of clay with materials that could improve its properties being used as a catalyst or adsorption ability or hydrophobic nature for adsorbing organic contaminants $[9,10]$. Efficiencies of these clay materials can be expanded remarkably by substituting exchangeable cations of clay with organic cations or grafting to yield hydrophobic organoclays [11-13]. This is like pillared interlayered clays (PILCs) and is based on a mechanism of cationic exchange in which robust inorganic molecules are introduced in the interlayer space of the clay minerals, forming oxides strongly bound to layers of the minerals [14]. However, PILCs remain hydrophilic, whereas organoclays make use of organic moieties for the intercalation process for making clay "hydrophobic", which can be used for organic contaminant adsorption.

In one particular study the removal of acid red dye from an aqueous system by a bentonite organoclay intercalated with hexadecyltrimethylammonium chloride was examined, and a maximum adsorption efficiency was observed at $\mathrm{pH} 13$ [15]. Another study claimed a composite clay adsorbent formed from poly-methyl methacrylate grafted onto tragacanth gum and bentonite was used to remove a number of anionic azo dyes like methyl orange, acid blue 113 and Congo red with improved efficiencies [16]. Thus, modified clays hold great promise for wastewater treatment.

Owing to low cost, high natural abundance, large specific surface area, excellent adsorption capacity, non-toxic nature and ease of modification, it is thus pertinent to replace costly and toxic adsorbents by organoclays for the treatment of wastewater [17]. With this consideration, we modified clay samples to organoclays by using hexadecylpyridinium chloride monohydrate (HDPCl. $\mathrm{H}_{2} \mathrm{O}$ ), cetyltrimethylammonium bromide (CTAB), and sodium dodecylsulfate (SDS) as modifiers. Under optimized conditions the asprepared organoclays were tested for the removal of brilliant green, ethyl violet and allura red dyes from wastewater. This work underscores the importance of the use of Pakistan-origin clays and the diverse nature of the modifiers for the efficient adsorption of various dyes. To the best of our knowledge, this is the first time for reporting various clay-modified adsorbents for the removal of allura red, ethyl violet, and brilliant green with high-efficiency of adsorption.

\section{Experimental}

\section{Materials and Methods}

All of the materials used were analytical grade, surfactants (hexadecylpyridinium chloride monohydrate ( $\mathrm{HDPCl} . \mathrm{H}_{2} \mathrm{O}$ ), cetyltrimethylammonium bromide (CTAB), and sodium dodecylsulfate (SDS)) and dyes brilliant green (BG), $\left(\mathrm{C}_{27} \mathrm{H}_{34} \mathrm{~N}_{2} \mathrm{O}_{4} \mathrm{~S}, \lambda_{\max } 632 \mathrm{~nm}\right)$ ethyl violet (EV) $\left(\mathrm{C}_{31} \mathrm{H}_{42} \mathrm{~N}_{3} \mathrm{Cl}, \lambda_{\max } 594 \mathrm{~nm}\right)$ and Allura red (AR) $\left(\mathrm{C}_{18} \mathrm{H}_{14} \mathrm{~N}_{2} \mathrm{O}_{8} \mathrm{~S}_{2} \cdot 2 \mathrm{Na}, \lambda_{\max } 500 \mathrm{~nm}\right)$. Commercially available bentonite clay is obtained from local market of Peshawar. For clay modification, $5 \mathrm{~g}$ of the clay was added to $100 \mathrm{~mL}$ of distilled water and stirred up to 6 hours for fine dispersion in water. Surfactant solution was formed by dissolving an appropriate amount (1.5x CEC) of each of the surfactants in $30 \mathrm{ml}$ of water. Sonication was run for 30 minutes for all to get a homogeneous solution. The surfactant solution was added slowly in the clay-water mixture and previously stirred for 6 hours, which was then further sonicated for $24 \mathrm{hrs}$, resulting in the synthesis of organoclay modified with the specific surfactant. All of experiments were performed at room temperature. The resulting surfactant-modified clay was washed with distilled water to remove the dissolved unreacted surfactant. The presence/absence of halides was confirmed through the halide ion test, performed by using 0.5 molar aqueous solution of $\mathrm{AgNO}_{3}$. The organoclays were dried at $110^{\circ} \mathrm{C}$ for 3 hours in an oven. The dried product was ground with the help of pestle and mortar and sieved through 200 mesh size and stored in a glass vial for further use. The organoclays obtained by modification with HDPCl. 
$\mathrm{H}_{2} \mathrm{O}, \mathrm{CTAB}$ and SDS were named $\mathrm{C} 3 \mathrm{H} 1, \mathrm{C} 2 \mathrm{CB} 1$ and C2S1 respectively.

\section{Characterization Techniques}

The synthesized organoclays along with the pristine montmorillonite clay were then subjected to characterization by XRD, FTIR, and SEM. For XRD characterization, all the clay samples were dried before analysis. After drying, the samples were pressed separately in a stainless steel sample holder. A Philips PANnalytical X'pert PRO diffractometer was used with $\mathrm{CuK} \alpha$ radiation $\left(\lambda=1.540598 \mathrm{~A}^{\circ}\right)$. The modified and unmodified clays were then subjected to FT-IR characterization and were recorded between 4000 and $400 \mathrm{~cm}^{-1}$ (Nicolet Nexus 870).

\section{Method of Dye Adsorption}

To study the adsorption of different dyes on organoclay, a known volume of dye solution was mixed with organoclay, followed by stirring of the mixture. A small quantity of adsorption mixture was withdrawn from the supernatant and centrifuged (Centrifuge model 800 ) to remove the organoclay particles. The clear solution decanted from the centrifuging tube was then analyzed with a UV-visible spectrophotometer (Shimadzu 1700 spectrophotometer). The decrease in the absorbance indicated adsorption of the dye on the surface of the organoclay. Each study was repeated thrice in order to get data set for further experiments. The following formula was used to obtained adsorption percentage.

$$
\% \text { Adsorption }=\frac{C_{i}-C_{e}}{C_{i}} \times 100
$$

The adsorption capacity $(q)$ was determined through:

$$
q=\frac{\left(C_{i}-C_{e}\right) V}{m}
$$

...where $c_{i}(\mathrm{mg} / \mathrm{L})=$ initial concentration of the dye, $c_{e}(\mathrm{mg} / \mathrm{L})=$ dye concentration at equilibrium,
$v(\mathrm{~L})=$ volume of the dye solution and $m=$ adsorbent in grams.

\section{Results and Discussion}

\section{Clay Characterization}

For the determination of the structural geometry and mineralogical composition of both unmodified and modified clays, X-ray diffraction analysis was performed. It was also used for the determination of both qualitative and quantitative phase analysis of multiphase mixtures. XRD offers information about the configuration of molecules and shows an increase in basal spacing between the layers of organoclay, which is caused by intercalated surfactant molecules. From the X-ray diffractograms shown in Fig. 1, a small increase $(1.91 \mathrm{~nm})$ can be observed in the basal spacing $\left(\mathrm{d}_{001}\right)$ for SDS-modified clay compared to the unmodified clay $(1.41 \mathrm{~nm})$. This small increase in the d-spacing can relate to the intercalation of a minute quantity of SDS into the clay layers, leading to a decrease in water of hydration, thus resulting in inducing some hydrophobic character in clay. However, in the case of CTAB and $\mathrm{HDPCl}$, the $\mathrm{d}_{001}$ spacing increased to $2.26 \mathrm{~nm}$ and $2.63 \mathrm{~nm}$ respectively, indicating more effective intercalation in the layers of the clay. This stronger clay-surfactant interaction may be due to electrostatic interaction of the positively charged head groups of these surfactant molecules with negative surface sites of clay and orientation/intercalation of the hydrophobic tails into the clay layers. The XRD results also suggest that clay modification with organic cations changes the crystallinity of the clay materials as evidenced from the increase in peak intensity [18].

The intercalation of surfactant molecules in the clay was also studied by FTIR spectroscopy. The FT-IR spectra of pristine clay (with and without modifications) are shown in Fig. 2. Pristine clay shows a frequency of 3619-3612 $\mathrm{cm}^{-1}$ corresponding to hydroxyl stretching band (hydroxyl sheet) in natural clay. In clay minerals the shape and position of the $-\mathrm{OH}$ stretching bands

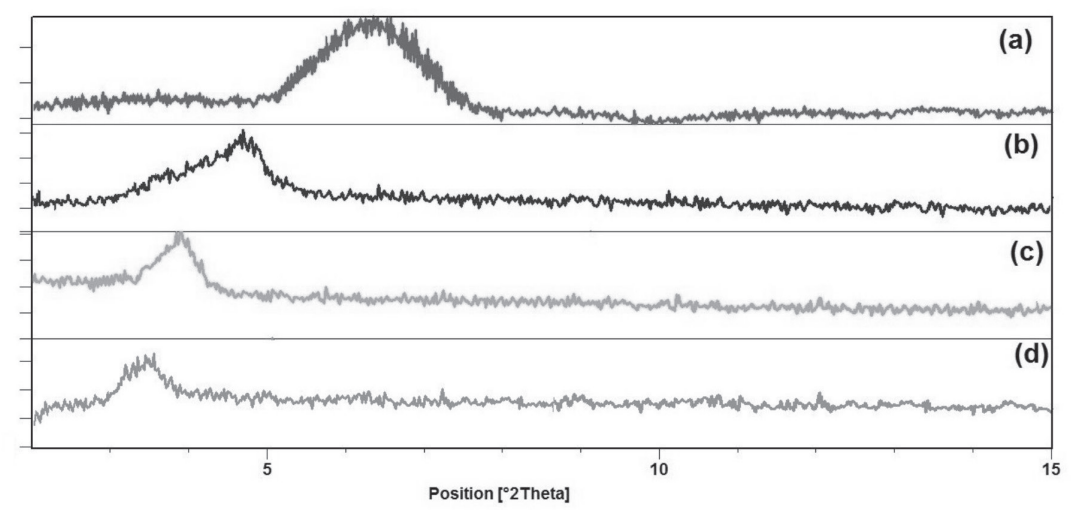

Fig. 1. XRD pattern of a) unmodified pristine clay and clay modified with SDS b), CTAB c) and HDPCl d). 
are strongly influenced by the coordination of the hydroxyl group to the octahedral atom. The broad peak in $1000-1004 \mathrm{~cm}^{-1}$ region corresponds to $\mathrm{Si}-\mathrm{O}$ planar stretching. The peak at $916 \mathrm{~cm}^{-1}$ corresponds to innersurface Al-OH deformation. After the treatment of clay with different surfactants, the absorption band for $\mathrm{OH}$ groups of the modified clay appear at lower wave numbers than the pristine clay. The bands between 2848-2964 $\mathrm{cm}^{-1}$ corresponding to the symmetric and antisymmetric stretching vibrations of the $-\mathrm{CH}_{2}$, $-\mathrm{CH}_{3}$ groups of surfactant's aliphatic chain ensure the formation of organoclay. The main peaks of the pure clay appearing in the modified clay suggest that the lattice of the clay remains intact even after modification $[19,20]$.
SEM images of unmodified clay (Fig. 3a, b) shows that the clay has large flakes/plates like structure, which has the capability to stick and stake on each other, making large lumps/particles that show the limited adsorption capacity of clay for dyes, etc. After modification of the clay it becomes more porous and fluffier (Fig. 3 c-f), and stabilized by the hydrophilic part of the surfactant, thus providing more room for the adsorption of dyes, etc., into the structure.

\section{Condition Optimization for Dye Adsorption}

For obtaining best conditions for dye removal, the effects of various variables were examined at room temperature $\left(25^{\circ} \mathrm{C}\right)$. The modified clays were then
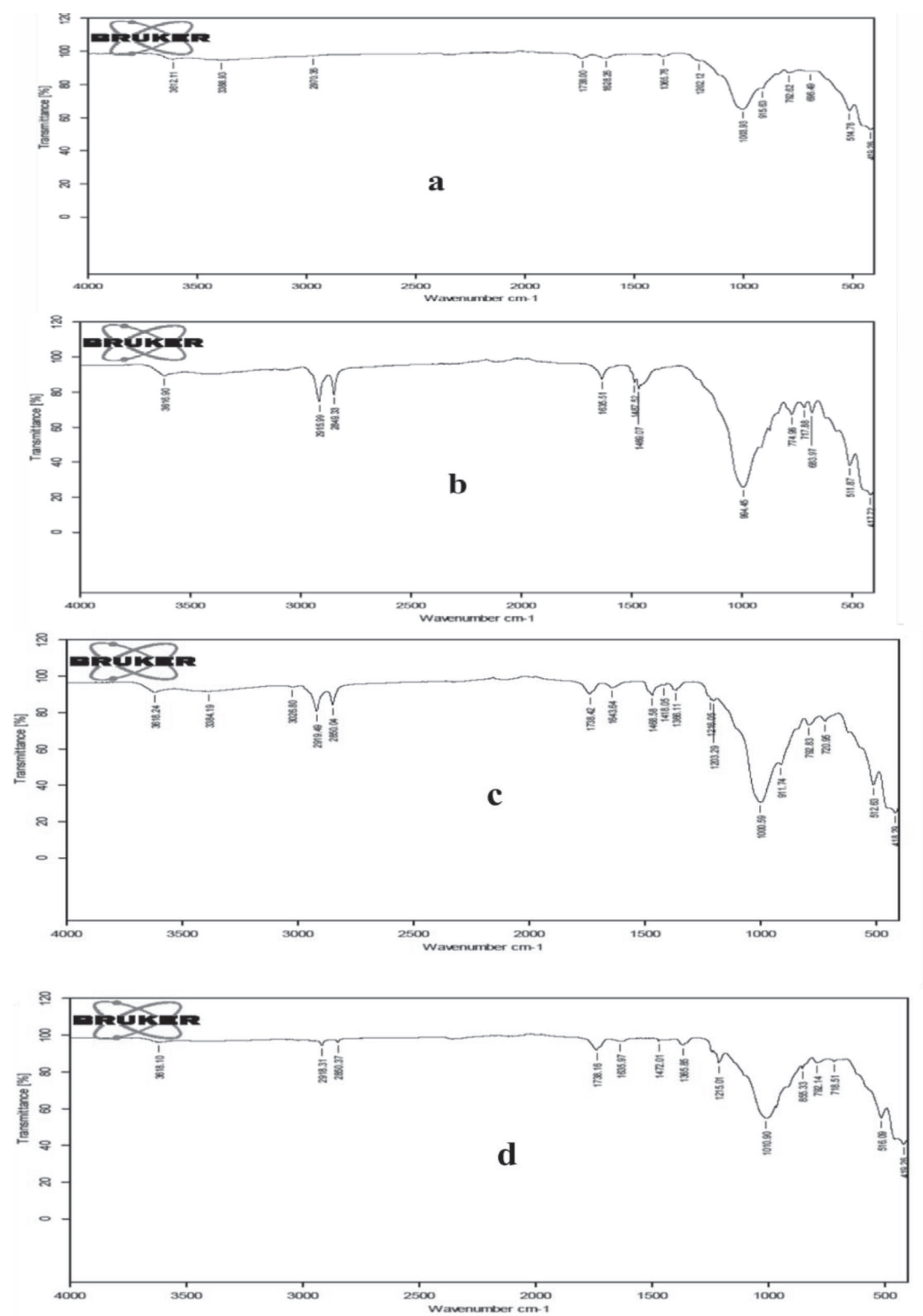

Fig. 2. FT-IR spectra of local bentonite a) without modification and modified with HDPCl b), CTAB c) and SDS d). 

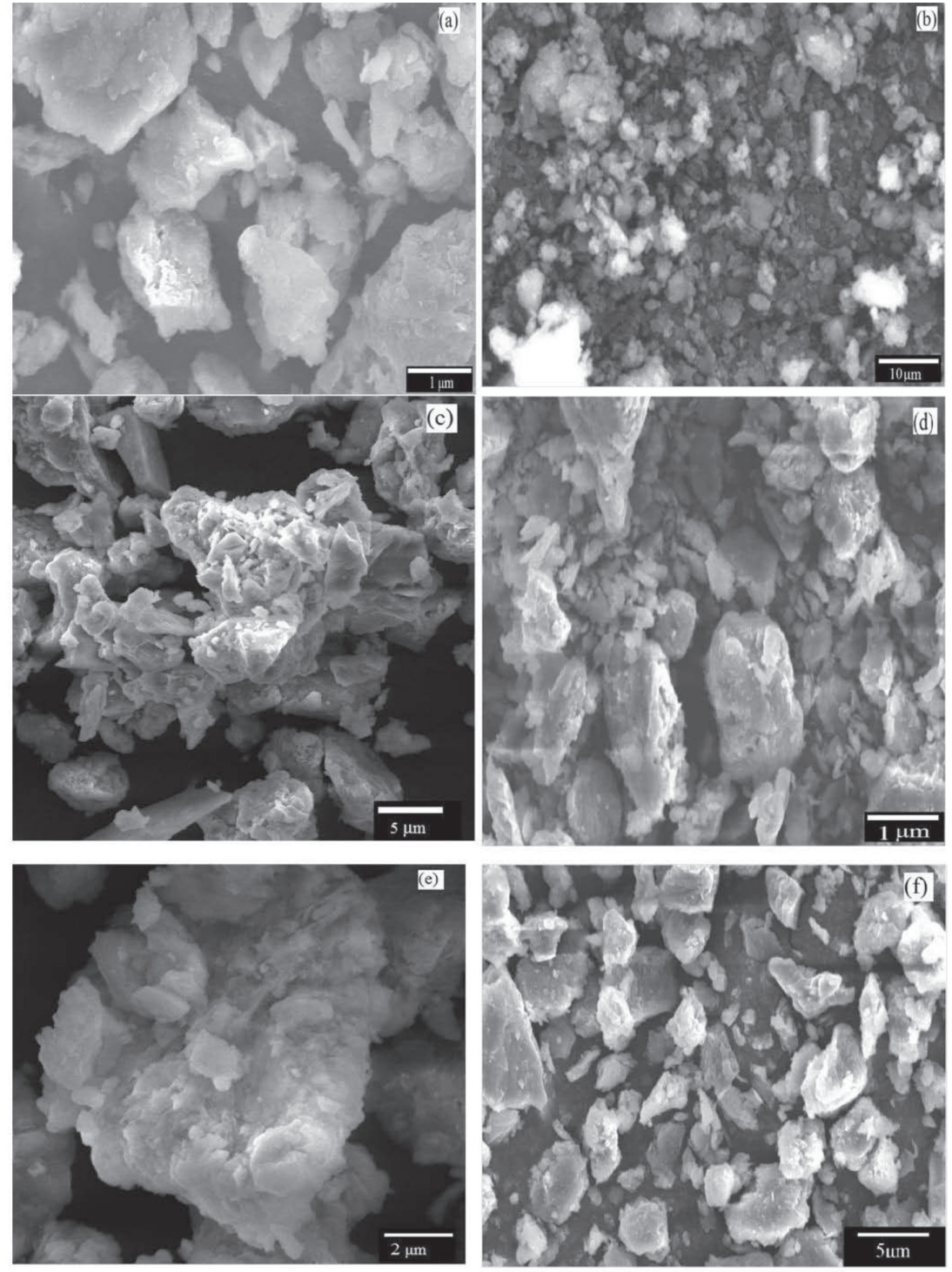

Fig. 3. SEM images of unmodified clay $(\mathrm{a}, \mathrm{b})$ and modified (c-f) at various magnifications.

tested for their sorption efficiency under optimized conditions. First the influence of $\mathrm{pH}$ was studied as this parameter disturbed the surface charge of the adsorbents, further affecting the degree of ionization of dyes in solution. Table 1 shows the influence of $\mathrm{pH}$ of the solution on the dye adsorption efficiency of organoclays in the $\mathrm{pH}$ range 3 to 10 . To figure out optimized $\mathrm{pH}$, a $0.1 \mathrm{~g}$ initial amount of adsorbent was used for a $70 \mathrm{mg} / \mathrm{L}(50 \mathrm{~mL})$ of allura red, $0.05 \mathrm{~g}$ of adsorbent for $50 \mathrm{mg} / \mathrm{L}(50 \mathrm{~mL})$ of brilliant green and $0.1 \mathrm{~g}$ of adsorbent for $50 \mathrm{mg} / \mathrm{L}(50 \mathrm{~mL})$ ethyl violet to analyze its absorption. Table 1 shows that the uptake profiles of all three dyes in organoclays (all type) with respect to change in $\mathrm{pH}$ are similar. A slightly acidic value of $\mathrm{pH} 5$ or 6 is required with little variation in sorption efficiency. The decrease in adsorption at $\mathrm{pH}$ above 5 may be related to competition of hydroxyl ions with dye anions for the active sites in the organoclay, as the overall surface of the organoclay $(\mathrm{C} 3 \mathrm{H} 1)$ is positive due to pyridinium sites of the surfactant. Under such conditions with regards to adsorption, only hydrophobic interactions are expected as protonation of the dye molecular ions exclude the possibility of electrostatic interactions.

The effect of contact time on dye adsorption ability of organoclays was also investigated. Table 1 shows the dependency of the percentage adsorption of all three dyes onto organoclays by varying the contact time. The obtained data show that the adsorption percentage increases by increasing time of contact between the dye and the organoclay. Although BG and EV show quick adsorption and reach the maximum within 15 minutes, the AR shows slow kinetics of adsorption and requires 60-80 mins to achieve maximum adsorption capacity, and no observable effect occurred with further increase in contact time.

After both $\mathrm{pH}$ and contact time effects, optimization of experiments was carried out to see the effect of dosage of adsorbents on the property of the as-synthesized clay. The amount of the adsorbents (C3H1, C2S1 and C2CB1) 
Table 1. Optimization parameters for the removal of selected dyes.

\begin{tabular}{|c|c|c|c|c|}
\hline Parameter & Adsorbent & Dyes & Range studied & Selected parameter \\
\hline \multirow{9}{*}{$\mathrm{pH}$} & \multirow{3}{*}{ Allura red } & $\mathrm{C} 3 \mathrm{H} 1$ & \multirow{3}{*}{$3-10$} & 5 \\
\hline & & $\mathrm{C} 2 \mathrm{CB} 1$ & & 5 \\
\hline & & $\mathrm{C} 2 \mathrm{~S} 1$ & & 6 \\
\hline & \multirow{3}{*}{ Brilliant green } & $\mathrm{C} 3 \mathrm{H} 1$ & \multirow{3}{*}{$3-10$} & 6 \\
\hline & & $\mathrm{C} 2 \mathrm{CB} 1$ & & 6 \\
\hline & & $\mathrm{C} 2 \mathrm{~S} 1$ & & 5 \\
\hline & \multirow{3}{*}{ Ethyl violet } & $\mathrm{C} 3 \mathrm{H} 1$ & \multirow{3}{*}{$3-10$} & 5 \\
\hline & & $\mathrm{C} 2 \mathrm{CB} 1$ & & 5 \\
\hline & & $\mathrm{C} 2 \mathrm{~S} 1$ & & 5 \\
\hline \multirow{9}{*}{ Time (mins) } & \multirow{3}{*}{ Allura red } & $\mathrm{C} 3 \mathrm{H} 1$ & \multirow{3}{*}{$05-90$} & 60 \\
\hline & & $\mathrm{C} 2 \mathrm{CB} 1$ & & 60 \\
\hline & & $\mathrm{C} 2 \mathrm{~S} 1$ & & 80 \\
\hline & \multirow{3}{*}{ Brilliant green } & $\mathrm{C} 3 \mathrm{H} 1$ & \multirow{3}{*}{$05-90$} & 15 \\
\hline & & $\mathrm{C} 2 \mathrm{CB} 1$ & & 15 \\
\hline & & $\mathrm{C} 2 \mathrm{~S} 1$ & & 15 \\
\hline & \multirow{3}{*}{ Ethyl violet } & $\mathrm{C} 3 \mathrm{H} 1$ & \multirow{3}{*}{$05-90$} & 15 \\
\hline & & $\mathrm{C} 2 \mathrm{CB} 1$ & & 15 \\
\hline & & $\mathrm{C} 2 \mathrm{~S} 1$ & & 15 \\
\hline \multirow{9}{*}{ Adsorbent dose (mg) } & \multirow{3}{*}{ Allura red } & $\mathrm{C} 3 \mathrm{H} 1$ & \multirow{3}{*}{$10-150$} & 100 \\
\hline & & $\mathrm{C} 2 \mathrm{CB} 1$ & & 100 \\
\hline & & $\mathrm{C} 2 \mathrm{~S} 1$ & & 100 \\
\hline & \multirow{3}{*}{ Brilliant green } & $\mathrm{C} 3 \mathrm{H} 1$ & \multirow{3}{*}{$10-150$} & 50 \\
\hline & & $\mathrm{C} 2 \mathrm{CB} 1$ & & 50 \\
\hline & & $\mathrm{C} 2 \mathrm{~S} 1$ & & 50 \\
\hline & \multirow{3}{*}{ Ethyl violet } & $\mathrm{C} 3 \mathrm{H} 1$ & \multirow{3}{*}{$10-150$} & 100 \\
\hline & & $\mathrm{C} 2 \mathrm{CB} 1$ & & 100 \\
\hline & & $\mathrm{C} 2 \mathrm{~S} 1$ & & 100 \\
\hline
\end{tabular}

varied from 0.01 to $0.15 \mathrm{~g}$ for $50 \mathrm{~mL}$ of each dye. The results are presented in Table 1, which illustrate that $0.05 \mathrm{~g}$ of organoclay is enough for the complete uptake of BG dye from the aqueous solution used, whereas $0.1 \mathrm{~g}$ is necessary for complete sorption of the other two dyes AR \& EV. Maximum uptake of the dyes occurred with a slight or no increase in the adsorption of the dye upon further increase in the amount of organoclays. The fast-initial uptake of the dyes is manifested as enhanced adsorption on the exposed surface and boundary layers of the organoclay as the majority of the binding sites on organoclay are expected to be available at the initial stage. The slow adsorption of dye after a certain time period may be related to the saturation of surface of organoclay with the respective dye and existence of repulsive forces among the dye molecules. Furthermore, the slow adsorption at equilibrium could be due to the low concentration of dyes at that saturation point.

\section{Study of Adsorption Kinetics}

To understand the kinetics of adsorption, two empirical kinetic models, i.e., pseudo first-order and pseudo second-order models were used. The experimentally observed adsorption capacity was correlated with that calculated from kinetic models. Matching of experimentally observed adsorption capacity with that calculated from kinetic models is judged from the value of linear regression coefficient represented by $\mathrm{R}^{2}$. The pseudo first-order model can be expressed as [21]: 
Table 2. Kinetic parameters for the adsorption of selected dyes on organoclays.

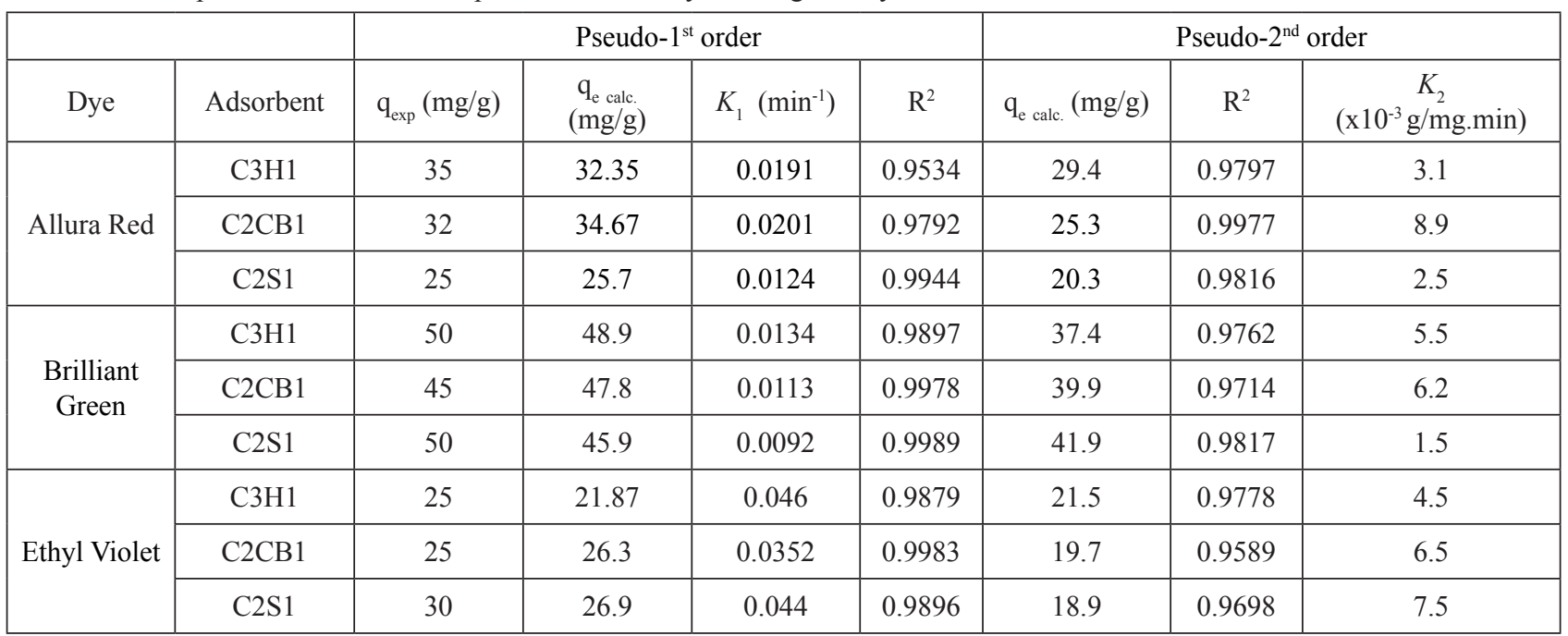

$$
\frac{d q_{t}}{d t}=k_{1}\left(q_{e}-q_{t}\right)
$$

The pseudo second-order kinetic model considers the chemical reaction important for controlling the rate of the reaction [22]. The empirical equation for this model is:

$$
\frac{d q_{t}}{d t}=k_{2}\left(q_{e}-q_{t}\right)^{2}
$$

Both models were used, and their outcomes are presented in Table 2. It is clear from the study that the pseudo first-order kinetic model in better in terms of $\mathrm{q}_{\mathrm{e}}$ (calculated), which is found to be similar to that of the $\mathrm{q}_{\mathrm{e}}$ (experimental) for all three types of dye onto the organoclays. In addition, the $\mathrm{k}_{1}$, and $\mathrm{R}^{2}$ were also found to be suitable for the pseudo first-order kinetic model.

\section{Adsorption Isotherm Models}

Various types of models (for isotherm data fittings) have been put forward to analyze the equilibrium adsorption data over the last three decades with different levels of acceptance. However, Langmuir and Freundlich isotherm models are still being used and have been found extensively in the literature and can be represented as follows:

$$
\frac{C_{e}}{q_{e}}=\frac{C_{e}}{q_{m}}+\frac{1}{K_{L} q_{m}}
$$

The Freundlich adsorption isotherm equation in linear form can be represented as:

\begin{tabular}{|c|c|c|c|c|c|c|c|c|c|}
\hline & & \multicolumn{5}{|c|}{ Langmuir } & \multicolumn{3}{|c|}{ Freundlich } \\
\hline Dye & Adsorbent & $\begin{array}{l}\mathrm{q}_{\mathrm{m}} \exp \\
(\mathrm{mg} / \mathrm{g})\end{array}$ & $\begin{array}{l}\mathrm{q}_{\mathrm{m} \text { calc. }} \\
(\mathrm{mg} / \mathrm{g})\end{array}$ & $\begin{array}{c}K_{L} \\
\mathrm{~L} / \mathrm{mg})\end{array}$ & $\mathrm{R}^{2}$ & $\mathrm{R}_{\mathrm{L}}$ & $\mathrm{n}_{\mathrm{F}}$ & $\begin{array}{c}K_{\mathrm{F}} \\
(\mathrm{mg} / \mathrm{g})\end{array}$ & $\mathrm{R}^{2}$ \\
\hline \multirow{3}{*}{ Allura Red } & $\mathrm{C} 3 \mathrm{H} 1$ & 60 & 60.4 & 0.77 & 0.9834 & 0.0082 & 4.67 & 28.8 & 0.9797 \\
\hline & $\mathrm{C} 2 \mathrm{CB} 1$ & 60 & 56.7 & 0.76 & 0.9892 & 0.0081 & 3.45 & 32.6 & 0.9977 \\
\hline & $\mathrm{C} 2 \mathrm{~S} 1$ & 55 & 55.8 & 0.79 & 0.9944 & 0.0078 & 3.89 & 36.7 & 0.9816 \\
\hline \multirow{3}{*}{$\begin{array}{c}\text { Brilliant } \\
\text { Green }\end{array}$} & C3H1 & 80 & 76.9 & 1.29 & 0.9897 & 0.0071 & 4.61 & 67.8 & 0.9762 \\
\hline & C2CB1 & 85 & 75.1 & 1.12 & 0.9978 & 0.0069 & 4.21 & 69.7 & 0.9914 \\
\hline & $\mathrm{C} 2 \mathrm{~S} 1$ & 75 & 78.9 & 1.07 & 0.9989 & 0.0073 & 4.01 & 70.7 & 0.9817 \\
\hline \multirow{3}{*}{ Ethyl Violet } & C3H1 & 40 & 38.7 & 1.18 & 0.9879 & 0.0064 & 3.57 & 27.6 & 0.9778 \\
\hline & $\mathrm{C} 2 \mathrm{CB} 1$ & 40 & 37.8 & 1.08 & 0.9983 & 0.0061 & 3.81 & 25.8 & 0.9589 \\
\hline & C2S1 & 35 & 35.9 & 1.12 & 0.9896 & 0.0068 & 4.12 & 26.6 & 0.9698 \\
\hline
\end{tabular}

$$
\ln q e=\ln K_{F}+\frac{1}{n_{F}} \ln C e
$$

Table 3. Adsorption isotherm parameters. 
Table 4. Comparison of various reported adsorbents with organoclays for the removal of dyes.

\begin{tabular}{|c|c|c|c|c|}
\hline Adsorbate & Adsorbent (g) & Adsorption capacity $(\mathrm{mg} / \mathrm{g})$ & Adsorption $(\%)$ & Reference \\
\hline Allura red & Heated pine wood at $1.0 \mathrm{~g}$ & 4.8 & - & {$[23]$} \\
\hline Allura red & Chitosan- tripolyphosphate & - & 98 & [24] \\
\hline Brilliant green & Lignin from Guava/Stearate $/ \mathrm{Al}_{2} \mathrm{O}_{3}$ at $0.1 \mathrm{~g}$ & 227 & 94.3 & {$[25]$} \\
\hline Brilliant green & Tannin gel at $0.6 \mathrm{~g}$ & 8.55 & 88.38 & {$[26]$} \\
\hline Brilliant green & Amine functionalized Tannin gel at $0.6 \mathrm{~g}$ & 20.41 & 94.05 & {$[26]$} \\
\hline Brilliant green & Solanum tuberosum Peels (Potato) at $0.6 \mathrm{~g}$ & - & 99.07 & {$[27]$} \\
\hline Brilliant green & activated carbon from acorn at $2 \mathrm{~g} / 100 \mathrm{ml}$ & 2.11 & $>90$ & {$[28]$} \\
\hline \multirow{3}{*}{ Allura Red } & $\mathrm{C} 3 \mathrm{H} 1$ & 60 & $>90$ & This work \\
\hline & $\mathrm{C} 2 \mathrm{CB} 1$ & 60 & $>90$ & This work \\
\hline & $\mathrm{C} 2 \mathrm{~S} 1$ & 55 & $>90$ & This work \\
\hline \multirow{3}{*}{ Brilliant Green } & $\mathrm{C} 3 \mathrm{H} 1$ & 80 & $>90$ & This work \\
\hline & $\mathrm{C} 2 \mathrm{CB} 1$ & 85 & $>90$ & This work \\
\hline & $\mathrm{C} 2 \mathrm{~S} 1$ & 75 & $>90$ & This work \\
\hline \multirow{3}{*}{ Ethyl Violet } & $\mathrm{C} 3 \mathrm{H} 1$ & 40 & $>90$ & This work \\
\hline & $\mathrm{C} 2 \mathrm{CB} 1$ & 40 & $>90$ & This work \\
\hline & $\mathrm{C} 2 \mathrm{~S} 1$ & 35 & $>90$ & This work \\
\hline
\end{tabular}

Table 3 reveals that both models are suitable for explaining the adsorption behavior of synthesized organoclays. The experimental maximum adsorption capacity $\mathrm{q}_{\mathrm{e}(\exp )}$ is nearly the same as that of $\mathrm{q}_{\mathrm{m}(\text { calc) }}$ from the Langmuir model, and the match is better than the Freundlich calculations $\left(K_{\mathrm{F}}\right)$. However, the regression coefficient $\left(\mathrm{R}^{2}\right)$ values of both models are similar for all three types of dyes. The results in Table 3 also show that the heterogeneity factor " $\mathrm{nF}$ " is larger than 1 , which indicates the favorable adsorption.

A dimensionless separation factor, $R_{\mathrm{L}}$ (from Langmuir equation), is also being used for adsorption favorability and can be calculated using equation:

$$
R_{L}=\frac{1}{\left(1+K_{L} C_{0}\right)}
$$

The numerical value of $R_{\mathrm{L}}$ can be used to show favorable $\left(R_{\mathrm{L}}\right.$ values lies between $\left.0 \& 1\right)$, unfavorable $\left(R_{\mathrm{L}}\right.$ value $\left.>1\right)$, linear $\left(R_{\mathrm{L}}\right.$ value $\left.=1\right)$ or irreversible $\left(R_{\mathrm{L}}\right.$ value $\left.=0\right)$ values. Based on our calculations, results in Table 3 show the favorable Langmuir adsorption process.

A comparison of these organoclays with various reported adsorbents [23-28] is given in Table 4. The results reveal promising candidature of our surfactantmodified clays for dye removal from water bodies.

\section{Conclusions}

The advent of the industrial revolution brought a boom in economics but also led to a devastating implication on the ecosystem by contaminating it from the effluents released from industries. Hence, in order to backtrack the devastating repercussions of the industrial discharge, especially on water bodies, organoclays seem a plausible, economical and viable option. To contribute in this area, we prepared three organoclays using clay of Pakistani origin modified with surfactants (HDPCl. $\mathrm{H}_{2} \mathrm{O}, \mathrm{CTAB}$ and SDS). The modification of clay was confirmed by XRD and FT-IR. Modification of clay by intercalating surfactant ions resulted in the development of the hydrophobic character and an increase in the interlayer spacing. All three modified clays showed high adsorption characteristics by removing $99.99 \%$ of all three dyes with an adsorption capacity ranging from 35 to $85 \mathrm{mg} / \mathrm{g}$. The time-dependent adsorption experiments showed that the rates of adsorption of dyes on organoclays were fast, adsorbing maximum amounts of dyes ranging from 15 to 80 mins contact time. The adsorption kinetic study revealed that the dye removal process is governed by a pseudo first-order mechanism. Thus, surfactant-modified clays are an excellent choice as cost-effective and efficient adsorbents for the purification of water from dye contaminants.

\section{Acknowledgements}

The authors are grateful to the Higher Education Commission of Pakistan for providing financial assistance under NRPU project No. 6172. The support of the Dean of Scientific Research at King Saud University through grant No. RG-1437-029 is also acknowledged. 


\section{Conflict of Interest Statement}

The authors declare that they have no known competing financial interests or personal relationships that could have appeared to influence the work reported in this paper.

\section{References}

1. WASEEM A., ARSHAD J., IQBAL F., SAJJAD A., MEHMOOD Z., MURTAZA G., Pollution Status of Pakistan: A Retrospective Review on Heavy Metal Contamination of Water, Soil, and Vegetables. Biomed Research International, 2014.

2. FAHEEM N., SAJJAD A., MEHMOOD Z., IQBAL F., MAHMOOD Q., MUNSIF S., WASEEM A., The pesticide exposure through fruits and meat in Pakistan. Fresenius Environ Bull 24, 4555, 2015.

3. ZHOU Y., LU J., ZHOU Y., LIU Y., Recent advances for dyes removal using novel adsorbents: A review. Environ Pollut 252, 352, 2019.

4. LU Y., CHEN J., BAI Y., GAO J., PENG M., Adsorption Properties of Methyl Orange in Water by Sheep Manure Biochar. Pol J Environ Stud 28, 3791, 2019.

5. KARADAG D., Wastewater Treatment by Anaerobic Fluidized Membrane Bioreactor. Pol J Environ Stud 28, 3551, 2019.

6. NAEEM, H., AJMAL M., MUNTHA S., AMBREEN J., SIDDIQ M., Synthesis and characterization of graphene oxide sheets integrated with gold nanoparticles and their applications to adsorptive removal and catalytic reduction of water contaminants. RSC Advances 8, 3599, 2018.

7. AJMAL, M., SIDDIQ M., AKTAS N., SAHINER N., Magnetic $\mathrm{Co}-\mathrm{Fe}$ bimetallic nanoparticle containing modifiable microgels for the removal of heavy metal ions, organic dyes and herbicides from aqueous media. RSC advances 5, 43873, 2015.

8. UDDIN M.K., A review on the adsorption of heavy metals by clay minerals, with special focus on the past decade. Chem Eng J 308, 438, 2017.

9. HAN H., RAFIQ M.K., ZHOU T., XU R., MAŠEK O., LI X. A critical review of clay-based composites with enhanced adsorption performance for metal and organic pollutants. J Hazard Mater 369, 780, 2019.

10. MUNIR M., AHMAD M., SAEED M., WASEEM A., REHAN M., NIZAMI A.-S., ZAFAR M., ARSHAD,M., SULTANA S., Sustainable production of bioenergy from novel non-edible seed oil (Prunus cerasoides) using bimetallic impregnated montmorillonite clay catalyst. Renvew Sust Energ Rev 109, 321, 2019.

11. ANIRUDHAN T., RAMACHANDRAN M., Adsorptive removal of basic dyes from aqueous solutions by surfactant modified bentonite clay (organoclay): kinetic and competitive adsorption isotherm. Process Saf Environ Prot 95, 215, 2015.

12. KAN T., JIANG X., ZHOU L., YANG M., DUAN M., LIU P., JIANG X., Removal of methyl orange from aqueous solutions using a bentonite modified with a new gemini surfactant. Appl Clay Sci 54, 184, 2011.

13. SAEED M., MUNIR M., NAFEES M., SHAH S.S.A., ULLAH H., WASEEM A., Synthesis, characterization and applications of silylation based grafted bentonites for the removal of Sudan dyes: Isothermal, kinetic and thermodynamic studies. Microporous Mesoporous Mater 291, 109697, 2020

14. BALOYI J., NTHO T., MOMA J., Synthesis and application of pillared clay heterogeneous catalysts for wastewater treatment: a review. RSC Advances 8, 5197, 2018.

15. MULLASSERY M.D., FERNANDEZ N.B., ANIRUDHAN T.S., Adsorptive removal of acid red from aqueous solutions by cationic surfactant-modified bentonite clay. Desalin Water Treat 56, 1929, 2015.

16. SADEGHI S., MOGHADDAM A.Z., MASSINAEI M., Novel tunable composites based on bentonite and modified tragacanth gum for removal of acid dyes from aqueous solutions. RSC Advances 5, 55731, 2015.

17. NAFEES M., WASEEM A., Organoclays as Sorbent Material for Phenolic Compounds: A Review. CLEAN 42, 1500,2014

18. LI J., ZHU L., CAI W., Characteristics of organobentonite prepared by microwave as a sorbent to organic contaminants in water. Colloids Surf, A 281, 177, 2006.

19. ULLAH H., NAFEES M., IQBAL F., AWAN M.S., SHAH A., WASEEM A., Adsorption Kinetics of Malachite Green and Methylene Blue from Aqueous Solutions Using Surfactant-modified Organoclays. Acta Chim Slov 64, 449, 2017.

20. NAFEES M., WASEEM A., KHAN A.R., Comparative study of laterite and bentonite based organoclays: implications of hydrophobic compounds remediation from aqueous solutions. ScientificWorldJournal 2013, 681769, 2013.

21. ALKAHTANI S.A., ABU-ALRUB S.S., MAHMOUD A.M., Adsorption of food coloring allura red dye (E129) from aqueous solutions using activated carbon. Int J Food Allied Sci 3, 10, 2017

22. DE MATTOS N.R., DE OLIVEIRA C.R., CAMARGO L.G.B., DA SILVA R.S.R., LAVALL R.L., Azo dye adsorption on anthracite: A view of thermodynamics, kinetics and cosmotropic effects. Sep Purif Technol 209, 806, 2019.

23. AL-GHOUTI M.A., ISSA A.A., AL-SAQARAT B.S., AL-REYAHI A.Y., AL-DEGS Y.S., Multivariate analysis of competitive adsorption of food dyes by activated pine wood. Desalin Water Treat 57, 27651, 2016.

24. SÁNCHEZ-DUARTE R.G., SÁNCHEZ-MACHADO D.I., LÓPEZ-CERVANTES J., CORREA-MURRIETA M.A., Adsorption of allura red dye by cross-linked chitosan from shrimp waste. Water Sci Technol 65, 618, 2012.

25. MOAWED E., WAHBA A., GABR R., Synthesis and application of LGB/St/A12O3 biocomposite for sensitive detection and efficient removal of brilliant green dye from wastewater. J Environ Chem Eng 6, 7225, 2018.

26. AKTER N., HOSSAIN M.A., HASSAN M.J., AMIN M., ELIAS M., RAHMAN M.M., ASIRI A.M., SIDDIQUEY I.A., HASNAT M.A. Amine modified tannin gel for adsorptive removal of Brilliant Green dye. J Environ Chem Eng 4, 1231, 2016.

27. REHMAN R., MAHMUD T., IRUM M., Brilliant green dye elimination from water using Psidium guajava leaves and Solanum tuberosum peels as adsorbents in environmentally benign way. J Chem-NY 2015, 2015.

28. GHAEDI M., HOSSAINIAN H., MONTAZEROZOHORI M., SHOKROLLAHI A., SHOJAIPOUR F., SOYLAK M., PURKAIT M. A novel acorn based adsorbent for the removal of brilliant green. Desalination 281, 226, 2011. 